\title{
Synthesis, crystal structure, and catalytic properties of 2,2'-bipyridyl-dicyano-palladium(II)
}

\author{
Xiaoli Tang, Longguan Zhu* \\ Department of Chemistry, Zhejiang University, Hangzhou, China \\ Email: ${ }^{*}$ chezlg@zju.edu.cn \\ Received 8 June 2013; revised 8 July 2013; accepted 24 July 2013 \\ Copyright (C) 2013 Xiaoli Tang, Longguan Zhu. This is an open access article distributed under the Creative Commons Attribution \\ License, which permits unrestricted use, distribution, and reproduction in any medium, provided the original work is properly cited.
}

\begin{abstract}
In the solvothermal condition, a Pd(II) complex with $a$ in situ synthesis ligand, $\left[\operatorname{Pd}\left(2,2^{\prime}-b i p y\right)_{2}(C N)_{2}\right](1)$ was obtained and characterized by elemental analysis, IR, UV, TG, and powder X-ray analysis. The single crystal $\mathrm{X}$-ray analysis showed that the title complex is different from the reported 2,2'-bipyridyl-dicyanopalladium(II) (2) in crystal system and structural parameters. The catalytic investigation for the reactions of the disproportionation of hydrogen peroxide and oxidation of sulfide showed that the complex 1 is an active homogeneous catalyst in the presence of imidazole and 2-sulfobenzoic acid, respectively.
\end{abstract}

Keywords: Synthesis; Thioanisol; Pd Complex;

Oxidation of Sulfide; Hydrogen Peroxide;

Disproportionation

\section{INTRODUCTION}

In situ ligand synthesis under hydro/solvothermal conditions has already yielded a large number of novel coordination complexes [1]. Under specific conditions, the solvents used in the solvothermal reaction may make some changes to produce new species [2]. Acetonitrile is a common organic solvent in the synthesis of coordination complexes, while this solvent can result in the $\mathrm{C}-\mathrm{C}$ bond cleavage under hydro/solvothermal conditions through the catalysis of metal ions, such as $\mathrm{Cu}$, $\mathrm{Mn}, \mathrm{Pb}, \mathrm{Ir}, \mathrm{Ru}$, and $\mathrm{Cd}$ [3]. Herein we report the first $\mathrm{C}-\mathrm{C}$ bond cleavage of acetonitrile in the presence of $\operatorname{Pd}(\mathrm{II})$ under solvothermal condition.

\section{EXPERIMENT}

\subsection{Reagents and Physical Measurements}

All chemicals were directly purchased from commercial resource with reagent grade and were used as received.

\footnotetext{
${ }^{*}$ Corresponding author.
}

Elemental analysis for $\mathrm{C}, \mathrm{H}$, and $\mathrm{N}$ were measured on a Perkin-Elmer analyzer model 1110. The infrared spectra were recorded on a Nicolet Nexus 470 infrared spectrophotometer in $\mathrm{KBr}$ pellets in the $400-4000 \mathrm{~cm}^{-1}$ region. Thermogravimetric analyses (TGA) were carried out using a Delta Series TA-SDT Q600 in nitrogen flow at a heating rate of $10^{\circ} \mathrm{C} / \mathrm{min}$ with $\mathrm{Al}_{2} \mathrm{O}_{3}$ crucibles. The UV-vis spectra were performed on a SPECORD 2000 $\mathrm{UV}$-vis spectrophotometer in $\mathrm{CH}_{3} \mathrm{OH}$ at room temperature. The powder $\mathrm{X}$-ray diffraction was measured by Rigaku D/MaX 2550PC with $\mathrm{Cu}-\mathrm{K} \alpha$ radiation. The GC data were recorded on a Fuli Gas Chromatography equipped with a DB-5 capillary column. All the standard substance used in GC were purchased from Alfa Aesar.

\subsection{Synthesis of Complex $\left[\operatorname{Pd}\left(2,2^{\prime} \text {-bipy }\right)_{2}(\mathrm{CN})_{2}\right]$}

(1)

A mixture of $\mathrm{Pd}\left(\mathrm{CH}_{3} \mathrm{COO}\right)_{2}(0.014 \mathrm{~g}, 0.062 \mathrm{mmol})$, 2-sulfobenzoic acid $(0.050 \mathrm{~g}, 0.25 \mathrm{mmol})$, and 2,2'bipyridine $(0.020 \mathrm{~g} 0.13 \mathrm{mmol})$ was dissolved in methanol/acetonitrile $(8 \mathrm{ml} / 8 \mathrm{ml})$ solution. The resulting mixture was sealed in a $25 \mathrm{ml}$ Teflon-lined autoclave and heated to $120^{\circ} \mathrm{C}$ for two days. Clear solution was set aside about two weeks at room temperature, then yellow plate-like crystals were obtained. No precipitation was observed in the absence of 2,2'-bipyridine or 2-sulfobenzoic acid. No complex was formed if $\mathrm{PdCl}_{2}$ was used in place of $\operatorname{Pd}\left(\mathrm{CH}_{3} \mathrm{COO}\right)_{2}$. Anal. Calcd (\%) for $\mathrm{C}_{12} \mathrm{H}_{8} \mathrm{~N}_{2} \mathrm{Pd}$ : C, 45.80; H, 2.54; N, 17.81. Found: C, 45.86; $\mathrm{H}, 2.92 ; \mathrm{N}, 17.92 . \mathrm{IR}\left(\mathrm{KBr}, \mathrm{cm}^{-1}\right): \mathrm{v}=3451(\mathrm{~s}), 3115(\mathrm{~m})$, $3082(\mathrm{~m}), 3053(\mathrm{~m}), 2133(\mathrm{~m}), 1606(\mathrm{~s}), 1450(\mathrm{~s})$, 1319(w), 1168 (w), 1038 (w), 773 (s), 727 (w), 415 (w).

The complex 1 can dissolve in methanol, acetonitrile, DMF, and DMSO, while it can not dissolve in $\mathrm{H}_{2} \mathrm{O}$, ethanol, and $\mathrm{CH}_{2} \mathrm{Cl}_{2}$.

\subsection{X-Ray Structure Determination}

The single crystal with suitable size for X-ray diffraction 
was selected for data collection by a Bruker Smart CCD area detector with graphite-monochromatized Mo-K $\alpha$ radiation $(\lambda=0.71073 \AA)$ at room temperature. The crystal was mounted on a glass fiber in a random orientation. Lorenz-polarization effect and secondary extinction were corrected [4]. The structure was solved by the heavyatom method and successive Fourier syntheses. Fullmatrix least-squares refinements on $\mathrm{F}^{2}$ were carried out using the SHELXL-97 package [5]. All non-H atoms were anisotropically refined. The structure analysis and drawing were helped by WinGX software [6]. The detailed crystallographic data and refinement parameters for complex $\mathbf{1}$ are listed in Table $\mathbf{1}$.

Table 1. Crystallographic data and refinement parameters for complex 1.

\begin{tabular}{|c|c|}
\hline Empirical formula & $\mathrm{C}_{12} \mathrm{H}_{8} \mathrm{~N}_{4} \mathrm{Pd}$ \\
\hline $\mathrm{Mr}$ & 314.62 \\
\hline Crystal system & Triclinic \\
\hline Space group & $\mathrm{P}-1$ \\
\hline Size $/ \mathrm{mm}^{3}$ & $0.05 \times 0.06 \times 0.08$ \\
\hline $\mathrm{a} / \AA$ & $6.9162(6)$ \\
\hline $\mathrm{b} / \AA ̊$ & $8.8442(7)$ \\
\hline $\mathrm{c} / \AA ̊$ & $9.4753(6)$ \\
\hline$\left.\alpha\right|^{\circ}$ & $86.578(6)$ \\
\hline$\beta /^{\circ}$ & $80.378(6)$ \\
\hline$\gamma^{\circ}$ & $74.574(7)$ \\
\hline $\mathrm{V} / \AA^{3}$ & $550.78(8)$ \\
\hline Z & 2 \\
\hline $\mathrm{D}_{\mathrm{c}} / \mathrm{Mg} \cdot \mathrm{m}^{-3}$ & 1.897 \\
\hline$\mu / \mathrm{mm}^{-1}$ & 1.664 \\
\hline$\theta$ range $/^{\circ}$ & $3.1-25.1$ \\
\hline Reflections collected & 3409 \\
\hline Unique reflections & 1958 \\
\hline Observed reflections & 1751 \\
\hline $\mathrm{R}_{\text {int }}$ & 0.034 \\
\hline parameters & 152 \\
\hline $\mathrm{F}(000)$ & 308 \\
\hline Temperature/K & $295(2)$ \\
\hline $\mathrm{R}_{1}, \mathrm{wR}_{2}[\mathrm{I}>2 \sigma(\mathrm{I}]$ & $0.033,0.064$ \\
\hline $\mathrm{R}_{1,}, \mathrm{R}_{2}$ [all data] & $0.041,0.071$ \\
\hline GOF & 0.860 \\
\hline largest difference peak and hole $/ \mathrm{e} \cdot \AA^{-3}$ & $0.431,-0.565$ \\
\hline
\end{tabular}

\subsection{Reaction of Sulfide Oxidation}

A $25 \mathrm{~mL}$ round-bottom flask was charged with a mixture of the catalyst $[0.015 \mathrm{mmol}$ of complex 1 or $0.015 \mathrm{mmol}$ of complex $\mathbf{1}$ and $0.01 \mathrm{mmol}$ of 2-sulfobenzoic acid $\left.\left(2-\mathrm{H}_{2} \mathrm{sb}\right)\right]$ in $\mathrm{CH}_{3} \mathrm{CN}(5 \mathrm{~mL})$ and the substrate methyl phenyl sulfide (MPS, $0.5 \mathrm{mmol}$ ). The mixture was stirred at room temperature for 10 minutes. Reaction was started by the addition of the corresponding amount of $\mathrm{H}_{2} \mathrm{O}_{2}$ solution $(30 \%, 1.5 \mathrm{mmol})$ under stir. The first sample was taken after 30 minutes and the later samples were taken at specified time with a fixed interval of $30 \mathrm{~min}$. Pellucid solution was taken, and diluted by 10 times immediately and measured by gas chromatography. Each catalyzed reaction was kept for 270 minutes.

\subsection{Hydrogen Peroxide Disproportionation Study}

A mixture of $1 \mathrm{~mL}$ aqueous solution of imidazole with the concentration of $0.1 \mathrm{~mol} / \mathrm{L}, 5 \mathrm{ml}$ of water, and $1 \mathrm{~mL}$ of DMSO containing the synthesized complex with the concentration of $10^{-3} \mathrm{~mol} / \mathrm{L}$ in a three-necked flask of 25 $\mathrm{mL}$ was stirred in a thermostated cell at room temperature. The flask was connected with a pump and a pressure gauge (APM-2D). With a vacuum pump, an average $5.0 \mathrm{kPa}$ pressure above the solution was obtained and kept. Then zero setting was done. At this moment, hydrogen peroxide $\left(1 \mathrm{ml}, \mathrm{H}_{2} \mathrm{O}_{2} 30 \% \mathrm{w} / \mathrm{w}\right)$ was introduced into the system by a syringe and immediately the time and the evolved oxygen pressure were recorded.

\section{RESULTS AND DISCUSSION}

\subsection{Powder X-Ray Analysis}

The purity of the synthesized complex 1 was confirmed by powder X-ray analysis. The measured XRD pattern is shown in Figure 1(a) and the calculated pattern derived from the single crystal data by Mercury [7] is depicted in Figure 1(b). These two patterns are nearly same, indicating that the bulk sample is pure.

\subsection{Single Crystal Structure}

The crystal structure of $\left[\mathrm{Pd}\left(2,2^{\prime}\right.\right.$-bipy $\left.)(\mathrm{CN})_{2}\right]$ (2) has been reported by Che and his coworkers in the orthogonal crystal system [8]. Complex 2 was directly synthesized by the reaction of $\operatorname{Pd}(\mathrm{CN})_{2}$ and 2,2'-bipyridine in dimethylformamide. The title complex crystallizes in triclinic system, indicating the different synthetic route led to the different packing arrangement. The Pd(II) center adopts a square-planar geometry completed by two $\mathrm{N}$ donors from two 2,2'-bipyridine and two $\mathrm{C}$ atoms from two cyano anions (Figure 2 and Table 2). The Pd-N bond lengths in $\mathbf{1}$ are significantly longer than those in $\mathbf{2}$, while the Pd-C bond lengths are remarkably shorter than 


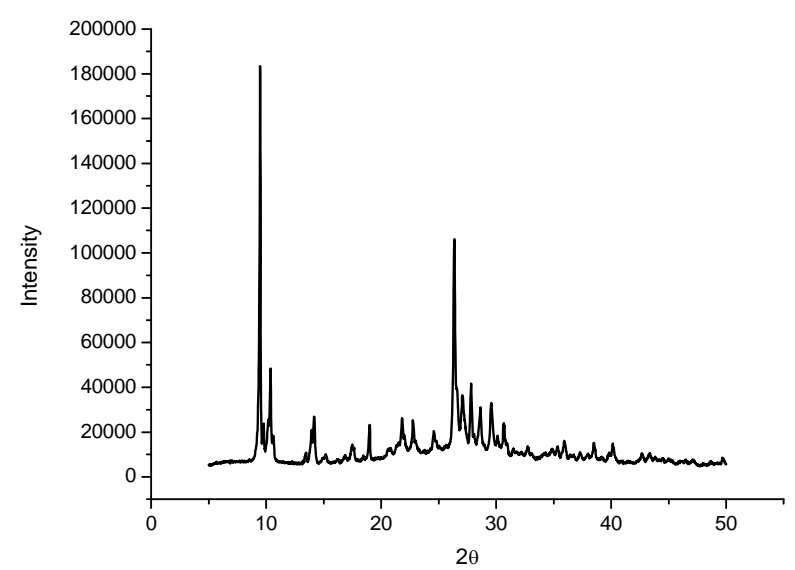

(a)

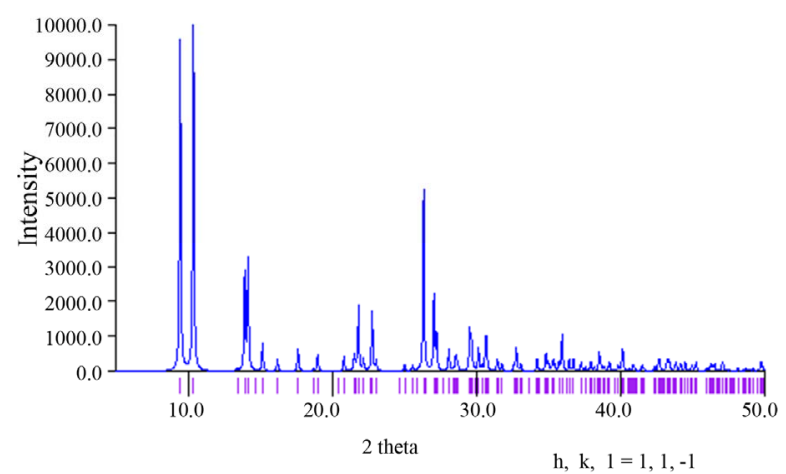

(b)

Figure 1. (a) The powder X-ray pattern of complex 1; (b) The simulated pattern of complex 1 derived from single crystal data.

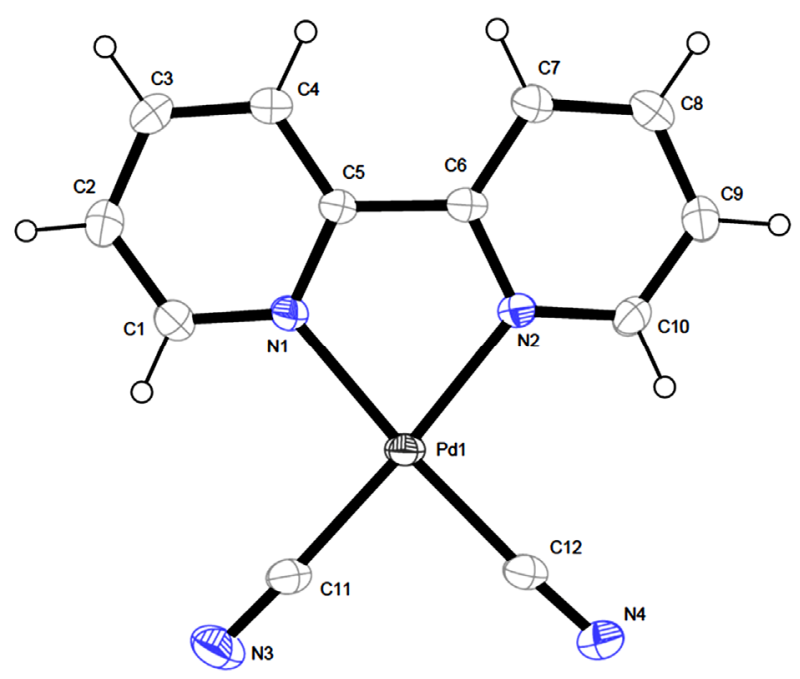

Figure 2. The view of molecular structure of complex 1 with atom labels and $40 \%$ probability displacement ellipsoids for non-H atoms.

those in 2. The distance of Pd...Pd in neibouring molecules in $\mathbf{1}$ is $3.5579(7) \AA$ which is slightly longer than that of 2 (3.3541(4) A. Complex 1 has no classic hydro- gen bond and aromatic $\pi-\pi$ interactions, while it has non-classic hydrogen bonds of C-H...N and short contact interactions of C-H...H-C, forming a 2D layer (Figure 3).

\subsection{TG Analysis}

The TG curve (Figure 4) was recorded from room temperature to $700^{\circ} \mathrm{C}$ in the nitrogen atmosphere. The complex 1 has no solvent and it can be stable up to $200^{\circ} \mathrm{C}$, then the complex starts to decompose.

\subsection{UV Spectrum}

The UV spectrum of complex $\mathbf{1}$ in methanol with the concentration of $4.675 \times 10^{-5} \mathrm{~mol} / \mathrm{L}$ at room temperature was shown in Figure 5. The spectrum shows two absorption peaks at $307 \mathrm{~nm}\left(\varepsilon=8342 \mathrm{dm}^{3} \cdot \mathrm{mol}^{-1} \cdot \mathrm{cm}^{-1}\right)$ and 320 $\mathrm{nm}\left(\varepsilon=8449 \mathrm{dm}^{3} \cdot \mathrm{mol}^{-1} \cdot \mathrm{cm}^{-1}\right)$. These bands can be assigned to characteristic $\pi-\pi *$ transitions [9]. The absorption peak of complex $\mathbf{1}$ is red-shifted compared with the absorption of 2,2'-bipy in $\mathrm{CH}_{3} \mathrm{CN}$ (282 nm), indicating that the coordination leads some change of the absorption.

\subsection{Catalytic Properties}

The disproportionation of hydrogen peroxide $[10,11]$ and oxidation of MPS $[12,13]$ were selected for the study of the catalytic properties of the complex 1 . The disproportionation of hydrogen peroxide was investigated by monitoring oxygen pressure. As is revealed from Figure 6, not only complex 1 but also imidazole has accelerated the reaction to the similar extent. Furthermore, existence of both 1 and imidazole (mz) have greatly accelerated the

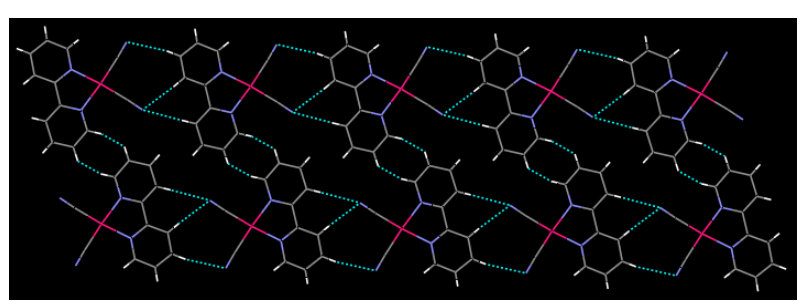

Figure 3. The view of the 2D layer formed by C-H...N and short contact interactions in complex $\mathbf{1}$.

Table 2. Selected bond lengths $(\AA)$ and angles $\left({ }^{\circ}\right)$ for complex 1.

\begin{tabular}{cccc}
\hline Pd1-N1 & $2.056(3)$ & Pd1-N2 & $2.055(3)$ \\
Pd1-Cl1 & $1.958(4)$ & Pd1-Cl2 & $1.956(4)$ \\
N1-Pd1-N2 & $79.54(12)$ & N1-Pd1-Cl1 & $96.58(15)$ \\
N1-Pd1-Cl2 & $175.22(15)$ & N2-Pd1-Cl1 & $175.78(15)$ \\
N2-Pd1-Cl2 & $95.92(15)$ & C11-Pd1-Cl2 & $87.91(17)$ \\
\hline
\end{tabular}




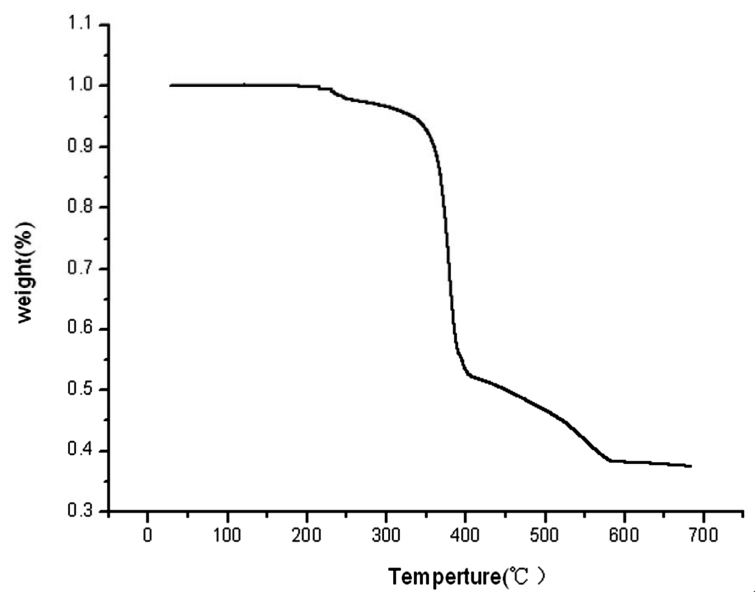

Figure 4. The TG curve of complex 1.

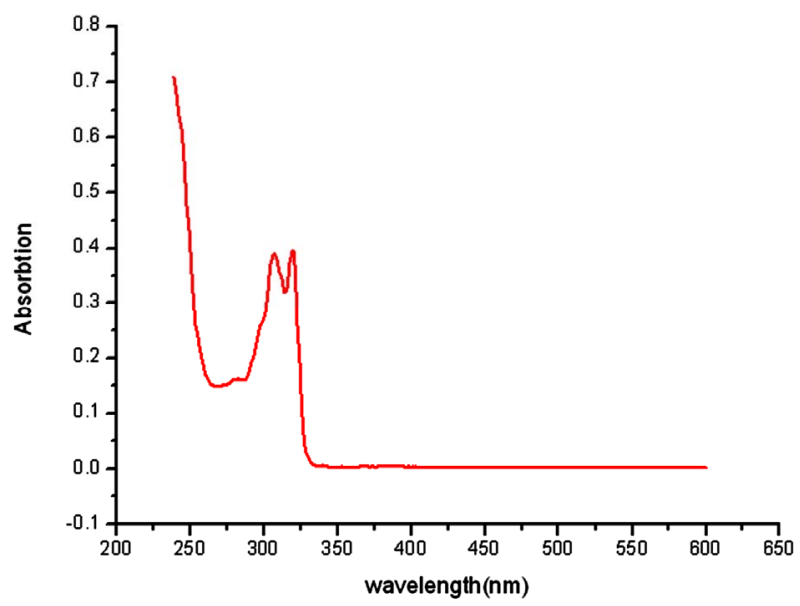

Figure 5. The UV spectrum of complex 1 in the methanol at room temperature.

reaction. The essential roles of bases have been mentioned in similar reactions [14]. We confirmed, and believe, that the base helps the subtraction of protons in $\mathrm{H}_{2} \mathrm{O}_{2}$ molecules, which may help the vicinity of $\mathrm{HO}_{2}{ }^{-}$as nucleophilic reagents to the active centers of $\mathrm{Pd}^{\mathrm{II}}$ catalyst [15].

The efficiency of activating MPS (methyl phenyl sulfide) oxygenation utilizing simple oxidant $\mathrm{H}_{2} \mathrm{O}_{2}$ in 3 equiv. was studied at ambient temperature $\left(23^{\circ} \mathrm{C} \pm 2^{\circ} \mathrm{C}\right)$ (Figure 7). Complex 1 exhibited the conversion of $45.8 \%$ and $56.8 \%$ selectivity for sulfoxide after $270 \mathrm{~min}$, and the addition of $2-\mathrm{H}_{2} \mathrm{sb}$ in the presence of complex 1 showed significantly conversion of $89.1 \%$ and $96.4 \%$ selectivity for sulfoxide (Figure 8), indicating that the complex $\mathbf{1}$ is an active catalyst in the reaction of oxidation of MPS and can promote the catalytic activity through the cooperation in the presence of $2-\mathrm{H}_{2} \mathrm{sb}$ [16].

\section{CONCLUSION}

In conclusion, we synthesized a Pd(II) complex with the

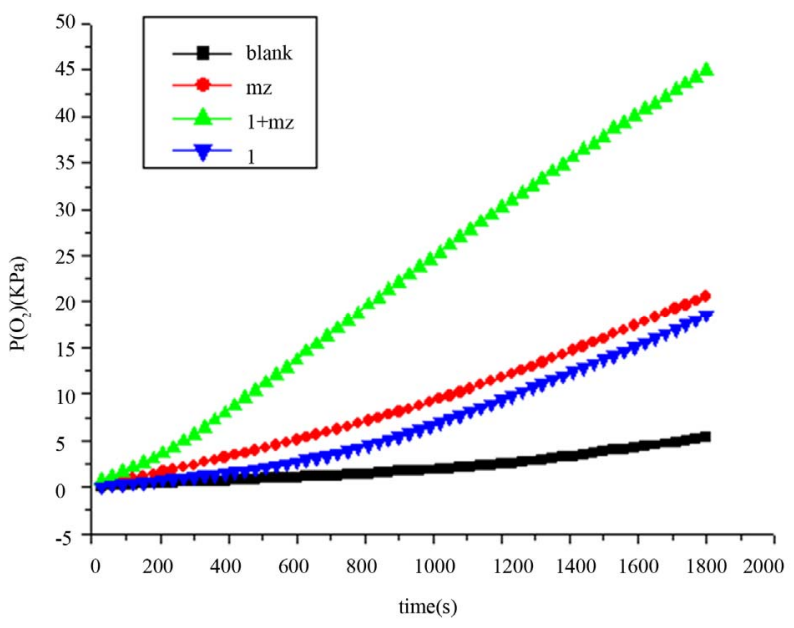

Figure 6. The disproportionation of hydrogen peroxide catalyzed by complex $\mathbf{1}$ and base.

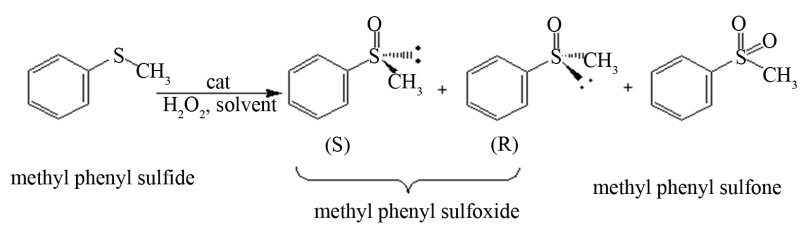

Figure 7. The scheme of the oxidation of methyl phenyl sulfide.

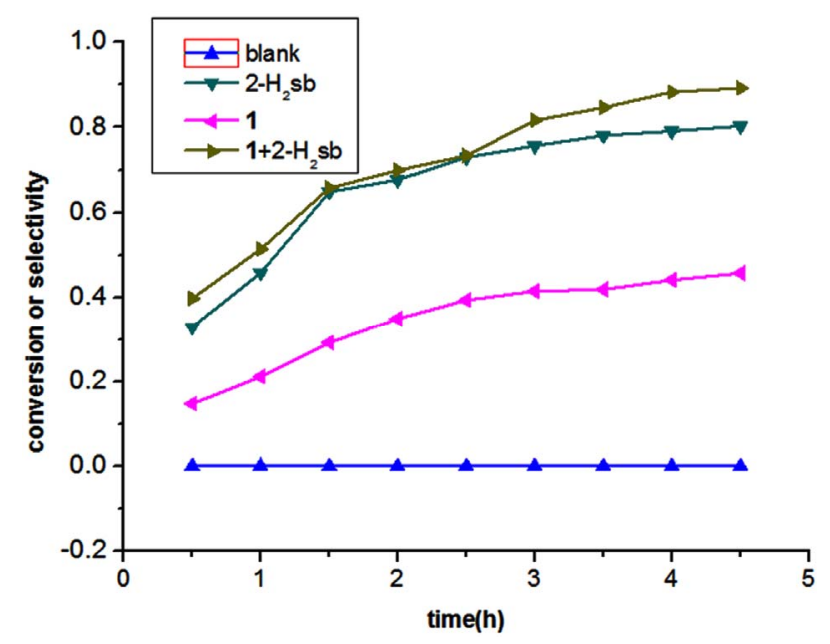

Figure 8. The oxidation of methyl phenyl sulfide by catalysts.

different crystal system from which is reported in the reference and characterized by the elemental analysis, IR, UV, TG, and powder X-ray analysis. The single crystal structure analysis showed that the complex $\mathbf{1}$ has some different structural characters from the complex 2 . The catalytic investigation for the reactions of oxidation of sulfide and the disproportionation of hydrogen peroxide showed the complex $\mathbf{1}$ is an active homogeneous catalyst, especially combined with $2-\mathrm{H}_{2} \mathrm{sb}$ and imidazole, respectively. 


\section{ACKNOWLEDGEMENTS}

The authors thank the National Natural Science Foundation of China (grant No. 21073157).

\section{REFERENCES}

[1] Chen, X.M. and Tong, M.L. (2007) Solvothermal in situ metal/ligand reactions: a new bridge between coordination chemistry and organic synthetic chemistry. Accounts of Chemical Research, 40, 162-170. http://dx.doi.org/10.1021/ar068084p

[2] Zhang, X.M. (2005) Hydro(solvo)thermal in situ ligand syntheses. Coordination Chemistry Reviews, 249, 12011219. http://dx.doi.org/10.1016/j.ccr.2005.01.004

[3] Zhu, Y.L., Qu, L.L., Zhang, J., Ge, G.W., Li, Y.Z., Du, H.B. and You, X.Z. (2011) In situ formation of an unprecedented 3D microporous $\mathrm{CuCN}$ coordination polymer based on a semirigid tetrahedral linker. Inorganic Chemistry Communications, 14, 1644-1647.

[4] Sheldrick, G.M. (1997) SADABS, Program for bruker area detector absorption correction. University of Göttingen, Göttingen.

[5] Sheldrick, G.M. (1997) SHELXL-97, program for crystal structure refinement. University of Göttingen, Göttingen.

[6] Farrugia, L.J. (1999) WinGX suite for small-molecule single-crystal crystallography. Journal of Applied Crystallography, 32, 837-838. http://dx.doi.org/10.1107/S0021889899006020

[7] Macrae, C.F., Edgington, P.R., McCabe, P., Pidcock, E., Shields, G.P., Taylor, R., Towler, M. and van de Streek, J. (2006) Mercury: Visualization and analysis of crystal structures. Journal of Applied Crystallography, 39, 453457. http://dx.doi.org/10.1107/S002188980600731X

[8] Che, C.C., He, L.Y., Poon, C.K. and Mak, T.C.W. (1989) Solid-state emission of dicyanoplatium(II) and palladium(II) complexes of substituted 2,2'-bipyridines and isomorphous $\mathrm{M}(\mathrm{bpy})(\mathrm{CN})_{2}$ (bpy=2,2'-bipyridine, $\mathrm{M}=\mathrm{Pt}$, Pd). Inorganic Chemistry, 28, 3081-3083.

[9] Yang, X.J., Janiak, C., Heinze, J., Drepper, F., Mayer, P., Piotrowski, H. and Klufers, P. (2001) Heteroleptic 5,5'disubstituted-2,2'-bipyridine complexes of ruthenium(II): spectral, electrochemical, and structural investigations. Inorganica Chimica Acta, 318, 103-116. http://dx.doi.org/10.1016/S0020-1693(01)00414-5
[10] Miao, X.H. and Zhu, L.G. (2010) Supramolecular assembly under the control of the chelating ligand for the $\mathrm{Mn}$ /bridging ligands/3-sulfobenzoate system and catalytic properties for the disproportionation of hydrogen peroxide. New Journal of Chemistry, 34, 2403-2414. http://dx.doi.org/10.1039/b9nj00428a

[11] Dubois, L., Caspar, R., Jacquamet, L., Petit, P. E., Charlot, M.F., Baffert, C., Collomb, M.N., Deronzier, A. and Latour, J.M. (2003) Binuclear manganese compounds of potential biological significance. Part 2. Mechanistic study of hydrogen peroxide disproportionation by dimanganese complexes: the two oxygen atoms of the peroxide end up in a dioxo intermediate. Inorganic Chemistry, 42, 4817-4827. http://dx.doi.org/10.1021/ic020646n

[12] Villalobos, L., Cao, Z., Fanwick, P.E. And Ren, T. (2012) Diruthenium(II,III) tetramidates as a new class of oxygenation catalysts. Dalton Transactions, 41, 644-650. http://dx.doi.org/10.1039/c1dt11530h

[13] Barker, J.E. and Ren, T. (2008) Diruthenium(II,III) bis(tetramethyl-1,3-benzenedipropionate) as a novel catalyst for tert-butyl hydroperoxide oxygenation. Inorganic Chemistry, 47, 2264-2266.

[14] Devereux, M., McCann, M., Leon, V., McKee, V. and Ball, R.J. (2002) Synthesis and catalytic activity of manganese(II) complexes of heterocyclic carboxylic acids: Xray crystal structures of $\left[\mathrm{Mn}(\text { pyr })_{2}\right]_{\mathrm{n}},\left[\mathrm{Mn}(\right.$ dipic $\left.)(\text { bipy })_{2}\right] \cdot /$ $4.5 \mathrm{H}_{2} \mathrm{O}$ and $[\mathrm{Mn}($ chedam $)($ bipy $)] \cdot / \mathrm{H}_{2} \mathrm{O}$ (pyr=/2-pyrazinecarboxylic acid; dipic =/pyridine-2,6-dicarboxylic acid; chedam_/chelidamic acid (4-hydroxypyridine-2,6-dicarboxylic acid); bipy =/2,2-bipyridine). Polyhedron, 21, 10631071. http://dx.doi.org/10.1016/S0277-5387(02)00842-2

[15] Viossat, V., Lemoine, P., Dayan, E., Dung, N.H. and Viossat, B. (2003) Synthesis, crystal structure and IR spectroscopy of $\mathrm{Mn}^{\mathrm{II}}(2-\mathrm{IC})_{2}(\mathrm{NC})(\mathrm{DMSO})$ and $\left[\mathrm{Mn}^{\mathrm{II}}(2-\mathrm{IC})_{2}\right.$ (phen) $\left.\left(\mathrm{H}_{2} \mathrm{O}\right)\right] \cdot \mathrm{DMA}$; (2-HIC, indole-2-carboxylic acid; phen, 1,10-phenanthroline; NC, 2,9-dimethyl-1,10-phenanthroline; DMSO, dimethyl sulfoxide; DMA, dimethyl acetamide); catalysts for the disproportionation of hydrogen. Polyhedron, 22, 1461-1470. http://dx.doi.org/10.1016/S0277-5387(03)00126-8

[16] Hu W.T. and Zhu, L.G. (2013) Study on the synthesis, crystal structure and catalytic activity for thioanisol of a ruthenium complex with 3-sulfobenzoate and 2,2'-bipyridine ligands. Chinese Journal of Inorganic Chemistry, 29, 1109-1114. 